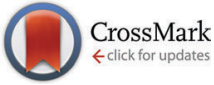

Cite this: Chem. Commun., 2016, 52,5289

Received 19th January 2016,

Accepted 14th March 2016

DOI: $10.1039 / \mathrm{c} 6 \mathrm{cc} 00536 \mathrm{e}$

www.rsc.org/chemcomm

\section{Full chirality transfer in the synthesis of hindered tertiary boronic esters under in situ lithiation-borylation conditions $\dagger$}

\author{
D. J. Blair, $\ddagger$ S. Zhong $\ddagger$ M. J. Hesse, N. Zabaleta, E. L. Myers and V. K. Aggarwal*
}

\begin{abstract}
Hindered tertiary neopentyl glycol boronic esters can be prepared by using in situ lithiation-borylation of enantiopure secondary benzylic carbamates at $-20^{\circ} \mathrm{C}$ with full chirality transfer.
\end{abstract}

Boronic esters are versatile intermediates in synthesis and there are now numerous methods for their preparation in enantioenriched form. ${ }^{1}$ In the case of tertiary boronic esters, which are more difficult to prepare, a number of stereoselective and stereospecific methods have emerged over recent years (Scheme 1a (ref. 2) and Scheme 1b (ref. 3)). The stereospecific lithiation-borylation of enantiopure secondary carbamates (Scheme 1b), which has been developed in our research group, ${ }^{3}$ has been employed by others ${ }^{4}$ and indeed has even been scaled up to $24 \mathrm{~kg}$. ${ }^{5}$ For this scale-up, the cryogenic conditions commonly employed $\left(s \mathrm{BuLi},-78{ }^{\circ} \mathrm{C}\right)^{6}$ presented challenges. However, Fandrick ${ }^{5}$ discovered that the carbamate could be deprotonated by a weaker base (LDA) and that this deprotonation could be conducted in the presence of pinacol boronic esters (in situ conditions) at elevated temperatures $\left(0{ }^{\circ} \mathrm{C}\right)$, to give the corresponding tertiary boronic esters with high levels of enantiospecificity (Scheme 1c). At such an elevated temperature, having the boronic ester present in the reaction mixture during the deprotonation prevents epimerisation and/or decomposition of lithiated carbamate $\mathbf{1}$.

With more hindered secondary boronic esters, such as iPrBpin, lower levels of enantiospecificity were observed, presumably due to reversible formation of boronate complex 2 . Such a process would return the sensitive lithiated carbamate $\mathbf{1}$, which would undergo racemisation and recombination with the boronic ester, thus leading to reduced stereoselectivity $\sim 80 \%$ es (Scheme $1 \mathrm{~b}$ ). We have previously found that the addition of $\mathrm{MgBr}_{2} /$ methanol following boronate complex formation enhances the rate of 1,2-migration and quenches any lithiated carbamate generated

School of Chemistry, University of Bristol, Cantock's Close, Bristol, BS8 1TS, UK. E-mail: v.aggarwal@bristol.ac.uk; Fax: +44 (0)117 929 8611;

Tel: +44 (0)117954 6315

$\dagger$ Electronic supplementary information (ESI) available: Full experimental details and characterisation. See DOI: 10.1039/c6cc00536e

\$ These authors contributed equally.

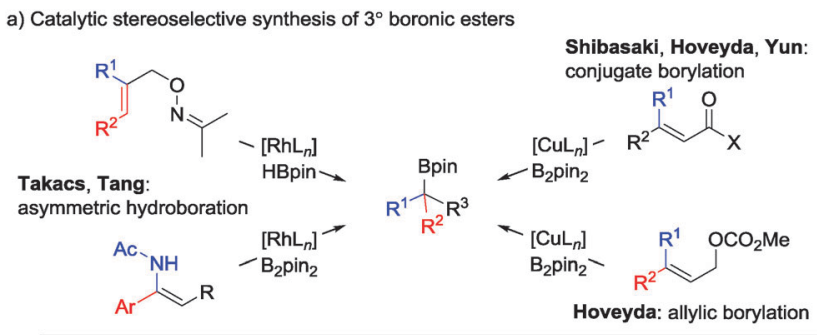

b) Aggarwal: Lithiation-borylation reaction

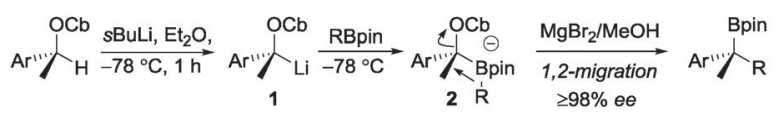

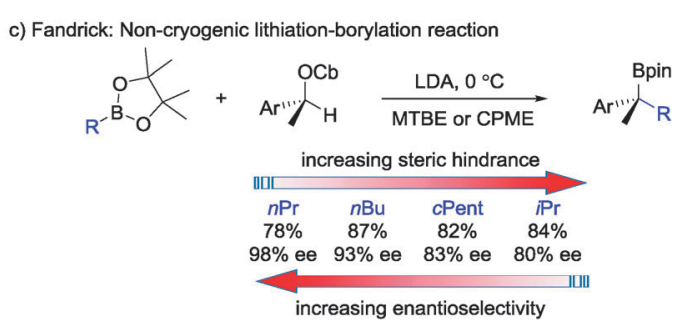

Scheme 1 State of the art: synthesis of tertiary boronic esters.

by the reverse process thereby leading to high yields and high stereoselectivity. ${ }^{3 a}$ Unfortunately, the addition of $\mathrm{MgBr}_{2}$ in methanol is not compatible with an in situ lithiation-borylation reaction. Herein, we address the issue of low selectivity with hindered boronic esters and show that by using neopentyl glycol boronic esters ${ }^{7}$ and LTMP (lithium 2,2,6,6-tetramethylpiperidine) as a base, high levels of enantiospecificity can now be achieved even with some of the most hindered boronic esters under noncryogenic conditions.

During our investigations of lithiation-borylation methodology we found that the nature of the ligand on boron sometimes affected the enantioselectivity of the process. ${ }^{3 b, 8}$ This is most dramatically illustrated in the case of the propargylic carbamate 3 where upon moving from the pinacol to the ethylene glycol based isopropyl boronic ester, enantiospecificity increased 


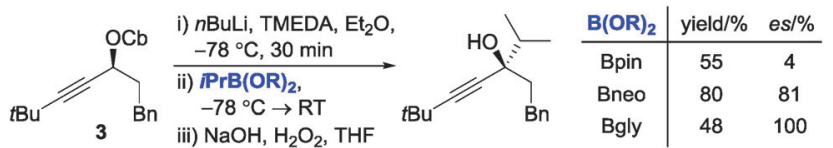

Scheme 2 Influence of the boron ligand on the stereochemical outcome of the lithiation-borylation of 3 ; these results are taken from ref. $8 a$ and are shown for comparison to results below (see Scheme 7).

from $4 \%$ to $100 \%$ (Scheme 2). ${ }^{8 a}$ Presumably, as the steric hindrance around boron was reduced, the boronate complex became less prone to reversibility and consequently the intermediate lithiated carbamate suffered less racemisation.

We therefore explored Fandrick's in situ conditions ${ }^{5}$ with iPrBneo in place of iPrBpin. These conditions gave tertiary alcohol 5 from 4 with full stereospecificity (100\% es, Scheme 3), a substantial improvement on that obtained using the pinacol boronate (80\% es). ${ }^{5}$ Other bases were tested and LTMP led to a higher yield (74\%). Further improvement in the yield was realised by reducing the temperature from $0{ }^{\circ} \mathrm{C}$ to $-20{ }^{\circ} \mathrm{C}$, resulting in 5 being isolated in $90 \%$ yield and $100 \%$ es.

Our optimised conditions were applied to a range of otherwise challenging carbamates (Scheme 4). As noted by Fandrick, the in situ conditions involving an amide base in place of an organolithium base enables aryl bromides and iodides to be employed, and so these were initially tested. Using our conditions, these substrates gave the corresponding tertiary alcohols 6 and 7 in high yields and

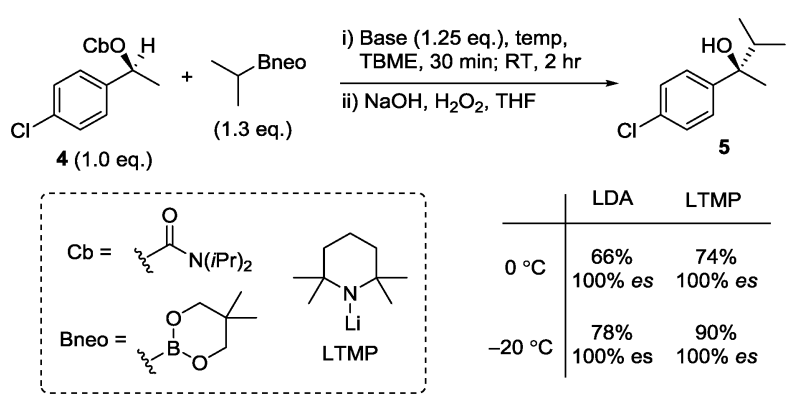

Scheme 3 Conditions for the homologation of neopentyl glycol boronic esters.

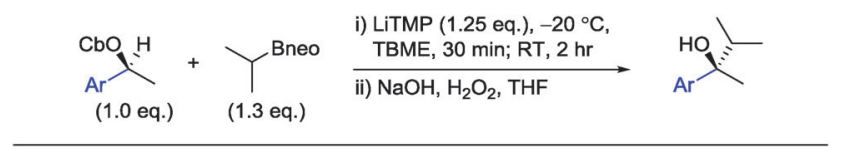

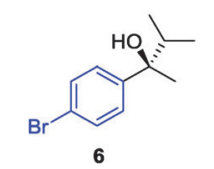

$95 \%, 100 \%$ es





$90 \%, 100 \%$ es

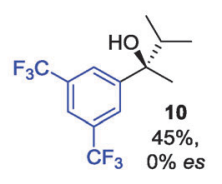

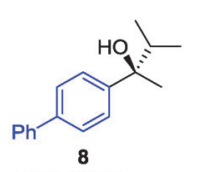

$96 \%, 100 \%$ es

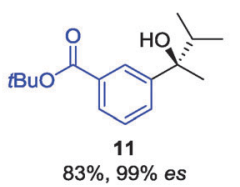

Scheme 4 Carbamate scope for the in situ lithiation-borylation of iPrBneo. complete enantiospecificity. The para-phenyl-substituted carbamate is especially prone to racemisation and using iPrBpin gave 8 in low enantiospecificity ( $83 \%$ es). However, using the neopentyl glycol boronic ester, 8 was again obtained in high yield and enantiospecificity. Electron-withdrawing groups on the aromatic ring engenders reversibility in the formation of the boronate complex, thus rendering the lithiated carbamate more prone to racemisation. We found that although a single meta- $\mathrm{CF}_{3}$ group was tolerated, enabling formation of $\mathbf{9}$ with excellent enantiospecificity, two meta$\mathrm{CF}_{3}$ groups was a step too far and led to essentially racemic product (10). ${ }^{9}$ A hindered ester was compatible with our conditions and gave tertiary alcohol $\mathbf{1 1}$ with complete enantiospecificity. This functional group would not have been compatible with the preformed lithiated carbamate. Unfortunately, the use of ortho-substituted benzylic carbamates did not lead to the expected products. In contrast, we have previously shown these carbamates do give the expected products in good yield and near-complete enantiospecificity when subjected to our cryogenic lithiation-borylation conditions. ${ }^{3 a, 10}$

Because the stereoselectivity of the in situ lithiation-borylation reaction is affected by the steric bulk of the boronic ester substituent ( $\mathrm{R}$ group), we tested a range of boronic esters of varying steric demand and compared both the pinacol (A) and neopentyl glycol (B) derivatives (Scheme 5). For unhindered $n \mathrm{Bu}(\mathbf{1 3})$ and cyclopropyl (14) boronic esters high enantiospecificity was observed by using pinacol boronic esters (98\% es), with neopentyl glycol boronic esters behaving similarly. Surprisingly, with unhindered allyl boronic esters (15) the pinacol derivative gave low es (82\%) whilst the neopentyl glycol ester provided essentially complete enantiospecificity.

To explore the limits in steric bulk that could be tolerated we turned to 3-pentyl boronic esters. ${ }^{11}$ Reaction of 3-pentyl-Bpin with 12 under our in situ conditions gave only traces of 16 with poor enantioselectivity. Simply switching to the corresponding neopentyl glycol ester significantly increased both the yield and selectivity, thus highlighting the advantages associated with neopentyl glycol derivatives, particularly in their application to hindered systems.

We have previously shown that secondary benzylic pinacol boronic esters form reversible boronate complexes with secondary benzylic carbamates leading to loss of both diastereo- and enantioselectivity. ${ }^{8 c}$ The application of in situ conditions to the reaction of $(R)$-1-phenylethyl pinacol boronic ester with 12 gave 17 in high yield (90\%, Scheme 6), high enantiospecificity (100\% es) with respect to

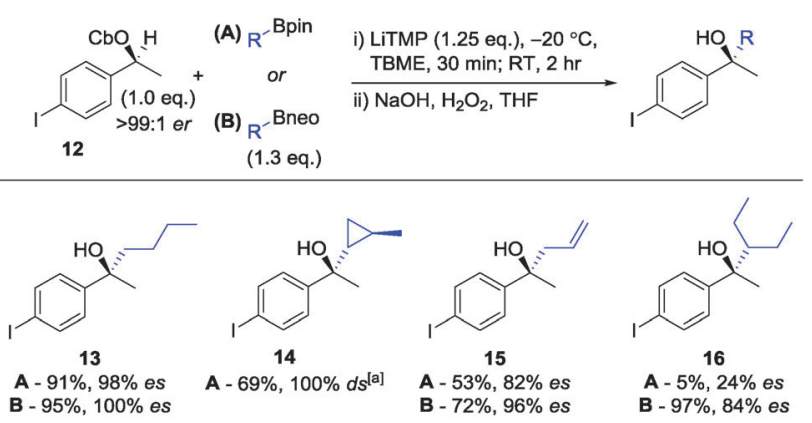

Scheme 5 Influence of boronic ester substituent on the in situ lithiationborylation reaction of $12 .{ }^{a}$ Because the use of the pinacol boronic ester gave tertiary alcohol 14 with complete diastereospecificity, the corresponding experiment with the neopentyl glycol boronic ester was not carried out. 


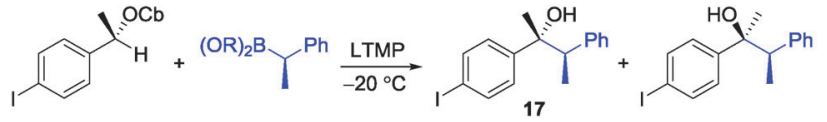

$\begin{array}{ccc}\begin{array}{c}12 \\ >99: 1\end{array} & \text { er - Bpin 98:2 er } & \text { A - 90\%, 100\% es, 85:15 dr } \\ & \text { B - Bneo 98:2 er } & \text { B - 76\%, 100\% es, 94:6 dr }\end{array}$

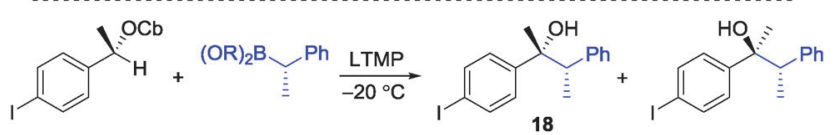

$\begin{array}{ccc}12 & \text { A - Bpin 96:4 er } & \text { A - 77\%, 100\% es, 95:5 dr } \\ >99: 1 \text { er } & \text { B - Bneo 96:4 er } & \text { B - } 65 \%, 100 \% \text { es, 98:2 dr }\end{array}$

Scheme 6 The influence of boronic ester diol on the stereochemical outcome of homologation of $(R)$ - and (S)-1-phenylethyl boronic esters with 12 under in situ conditions using pinacol (A) and neopentyl glycol (B) boronic esters.

the boronic ester starting material, but low diastereoselectivity (85:15 dr). ${ }^{12}$ Simply switching to the corresponding neopentyl glycol boronic ester gave 17 in 94:6 dr, 100\% es and high yield. In contrast, reaction of $\mathbf{1 2}$ with both pinacol and neopentyl glycol (S)-1-phenylethyl boronic esters gave 18 in high yield and selectivity ( $\geq 95: 5 \mathrm{dr}, 100 \%$ es). ${ }^{13}$ Evidently, there is a significant matched/ mis-matched effect operating under the reversible conditions with the pinacol boronic esters that can be minimised by using the neopentyl glycol boronic esters.

As noted above, for substrates that are especially prone to reversibility in boronate formation and therefore racemisation (e.g. 8), the in situ conditions using neopentyl glycol boronic esters can lead to considerably higher levels of enantiospecificity. We therefore tested our in situ conditions with the secondary propargylic carbamate 19 , a substrate that only gave $81 \%$ es under conditions where the lithiated carbamate was preformed ${ }^{8 a}$ (Scheme 7). Under the new in situ conditions the tertiary propargylic alcohol $\mathbf{2 0}$ was obtained in high yield and excellent enantiospecificity (98\% es). ${ }^{14}$ This highlights the broad applicability of the new in situ lithiation-borylation protocol. ${ }^{15}$

In summary, we have found that almost complete enantiospecificity can be achieved in the lithiation-borylation reactions of secondary benzylic carbamates under in situ conditions when neopentyl glycol boronic esters are used in place of pinacol boronic esters. These conditions expand the range of tertiary boronic esters that can be prepared with very high selectivity with both increased functional-group and steric tolerance. The improved stereoselectivity results from reduced reversibility in boronate complex formation, a process that otherwise causes racemisation of the sensitive lithiated carbamate.

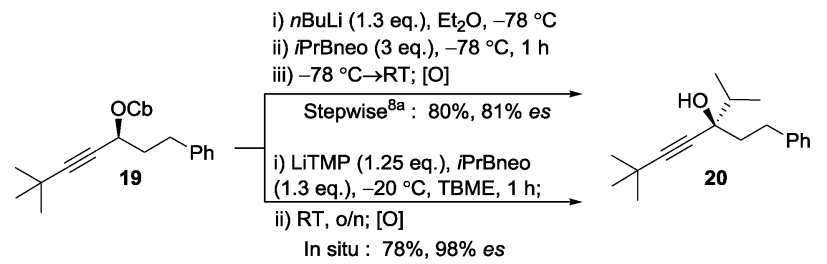

Scheme 7 Enhanced stereospecificity using in situ conditions in the lithiation-borylation reaction of secondary propargylic carbamates.
We thank European Research Council (FP7/2007-2013, ERC grant no. 246785; H2020/2015-2020, ERC grant no. 670668), and EPSRC (EP/I038071/1) for financial support. N. Z. thanks UPV/EHU predoctoral mobility program. S. Z. thanks the EPSRC-funded Bristol Synthesis Centre for Doctoral Training (EP/L015366/1).

\section{Notes and references}

1 (a) Boronic Acids: Preparation and Applications in Organic Synthesis, Medicine and Materials (Volume 1 and 2), ed. D. G. Hall, Wiley-VCH Verlag GmbH \& Co. KGaA, 2nd edn, 2011; (b) Synthesis and Application of Organoboron Compounds, ed. E. Fernandez and A. Whiting, Springer International Publishing, 2015.

2 (a) I. H. Chen, L. Yin, W. Itano, M. Kanai and M. Shibasaki, J. Am. Chem. Soc., 2009, 131, 6746; (b) J. M. O’Brien, K. Lee and A. H. Hoveyda, J. Am. Chem. Soc., 2010, 132, 10630; (c) X. Feng and J. Yun, Chem. - Eur. J., 2010, 16, 13609; (d) S. Radomkit and A. H. Hoveyda, Angew. Chem., Int. Ed., 2014, 126, 3455; (e) N. Hu, G. Zhao, Y. Zhang, X. Liu, G. Li and W. Tang, J. Am. Chem. Soc., 2015, 137, 6746; For recent syntheses of racemic tertiary boronic esters see: $(f)$ A. J. Wommack and J. S. Kingsbury, Tetrahedron Lett., 2014, 55, 3163; (g) K. Hong, X. Liu and J. P. Morken, J. Am. Chem. Soc., 2014, 136, 10581.

3 (a) J. L. Stymiest, V. Bagutski, R. M. French and V. K. Aggarwal, Nature, 2008, 456, 778; (b) V. Bagutski, R. M. French and V. K. Aggarwal, Angew. Chem., Int. Ed., 2010, 49, 5142; For reviews see: (c) S. P. Thomas, R. M. French, V. Jheengut and V. K. Aggarwal, Chem. Rec., 2009, 9, 24; (d) D. Leonori and V. K. Aggarwal, Acc. Chem. Res., 2014, 47, 3174.

4 (a) B. W. Glasspoole, K. Ghozati, J. W. Moir and C. M. Crudden, Chem. Commun., 2012, 48, 1230; (b) R. D. Grigg, J. W. Rigoli, R. Van Hoveln, S. Neale and J. M. Schomaker, Chem. - Eur. J., 2012, 18, 9391; (c) P. A. Evans, S. Oliver and J. Chae, J. Am. Chem. Soc., 2012, 134, 19314; (d) P. A. Evans and S. Oliver, Org. Lett., 2013, 15, 5626; $(e)$ Y. Li, S. Chakrabarty and A. Studer, Angew. Chem., Int. Ed., 2015, 54, 3587; $(f)$ B. W. H. Turnbull, S. Oliver and P. A. Evans, J. Am. Chem. Soc., 2015, 137, 15374.

5 (a) K. R. Fandrick, J. A. Mulder, N. D. Patel, J. Gao, M. Konrad, E. Archer, F. G. Buono, A. Duran, R. Schmid, J. Daeubler, J.-N. Desrosier, X. Zeng, S. Rodriguez, S. Ma, B. Qu, Z. Li, D. R. Fandrick, N. Grinberg, H. Lee, T. Dosanac, H. Takahashi, Z. Chen, A. Bartolozzi, P. Nemoto, C. A. Busacca, J. J. Song, N. K. Yee, P. E. Mahaney and C. H. Senanayake, J. Org. Chem., 2014, 80, 1651; (b) K. R. Fandrick, N. D. Patel, J. A. Mulder, J. Gao, M. Konrad, E. Archer, F. G. Buono, A. Duran, R. Schmid, J. Daeubler, D. R. Fandrick, S. Ma, N. Grinber, H. Lee, C. A. Busacca, J. J. Song, N. K. Yee and C. H. Senanayake, Org. Lett., 2014, 16, 4360; (c) K. R. Fandrick, J. J. Gao, J. A. Mulder, N. D. Patel and X. Zeng, WO 2013119751, 2013.

6 (a) D. Hoppe, A. Carstens and T. Kramer, Angew. Chem., Int. Ed. Engl., 1990, 29, 1424; (b) A. Carstens and D. Hoppe, Tetrahedron, 1994, 50, 6097.

7 Neopentyl glycol boronates, which are less sterically hindered than the corresponding pinacol boronic esters, have found application in other organoboron transformations besides lithiation-borylation. For selected examples, see: (a) F. J. Lawlor, N. C. Norman, N. L. Pickett, E. G. Robins, P. Nguyen, G. Lesley, T. B. Marder, J. A. Ashmore and J. C. Green, Inorg. Chem., 1998, 37, 5282; (b) S. Ueno, N. Chatani and F. Kakiuchi, J. Am. Chem. Soc., 2007, 129, 6098; (c) K. Huang, D.-G. Yu, S.-F. Zheng, Z.-H. Wu and Z.-J. Shi, Chem. - Eur. J., 2011, 17, 786; (d) N. Zhang, D. J. Hoffman, N. Gutsche, J. Gupta and V. Percec, J. Org. Chem., 2012, 77, 595; (e) M. Tobisu, H. Kinuta, Y. Kita, E. Rémond and N. Chatani, J. Am. Chem. Soc., 2012, 134, 115; $(f)$ S. C. Matthew, B. W. Glasspoole, P. Eisenberger and C. M. Crudden, J. Am. Chem. Soc., 2014, 136, 5828; $(g)$ X.-W. Liu, J. Echavarren, C. Zarate and R. Martin, J. Am. Chem. Soc., 2015, 137, 12470; $(h)$ K. Feeney, G. Berionni, H. Mayr and V. K. Aggarwal, Org. Lett., 2015, 17, 2614; (i) C. Zarate, R. Manzano and R. Martin, J. Am. Chem. Soc., 2015, 137, 6754; $(j)$ L. Fang, L. Yan, F. Haeffner and J. P. Morken, J. Am. Chem. Soc., 2016, 138, 2508.

8 (a) B. M. Partridge, L. Chausset-Boissarie, M. Burns, A. P. Pulis and V. K. Aggarwal, Angew. Chem., Int. Ed., 2012, 51, 11795; (b) A. P. Pulis, D. J. Blair, E. Torres and V. K. Aggarwal, J. Am. Chem. Soc., 2013, 135, 16054; (c) S. Roesner, D. J. Blair and V. K. Aggarwal, Chem. Sci., 2015, 6, 3718. 
9 Reducing the steric bulk of the boronic ester reaction partner from iPr to Et had no effect on the stereochemical outcome.

10 The ortho-bromo isomer of 6 and an ortho-methyl substrate (not depicted), did not lead to the expected products. The former substrate did not react whereas the latter gave a mixture of isomeric species derived from its fragmentation into the corresponding ortho-quinodimethane followed by $(4+2)$ cycloaddition. See the ESI, $\dagger$ for further details on this side reaction.

$11 \mathrm{tBu}$ boronic esters were also tested but both pinacol and neopentyl glycol esters failed to react under the in situ conditions.

12 Enantiospecificity was determined for the major diastereoisomer.

13 No epimerisation of the secondary boronic ester stereocentre was observed in either $\mathbf{1 7}$ or $\mathbf{1 8}$ with pinacol or neopentyl glycol esters. The presence of an electron-withdrawing group in $\mathbf{1 2}$ must bias the corresponding boronate complex towards fragmentation to $\mathrm{Li}-\mathbf{1 2}$ rather than fragmentation of the $\mathrm{C}-\mathrm{B}$ bond of the secondary boronic ester substrate to form a benzylic anion.

14 For the propargylic carbamates, unfortunately the use of a trialkylsilyl substituent in place of a $t$-butyl group led to desilylated products not incorporating the boronic ester organic group.

15 We have previously shown that when substituted allylic carbamates are subjected to lithiation-borylation reactions under cryogenic conditions with neopentyl glycol boronic esters as partners, a mixture of products derived from $\alpha$ - and $\gamma$-borylation are obtained: (a) A. P. Pulis, PhD thesis, University of Bristol, 2012. However, the use of pinacol boronic esters lead to predominantly the required $\alpha$-borylation: (b) A. P. Pulis and V. K. Aggarwal, J. Am. Chem. Soc., 2012, 134, 7570. 